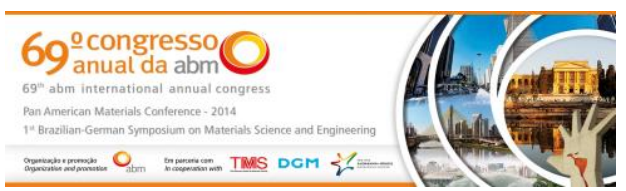

Tema: Tratamento térmico

\title{
CARACTERIZAÇÃO MICROESTRUTURAL DE UM AÇO SAE 1070 OBTIDO VIA PROCESSAMENTO TERMOMECÂNICO PARA FABRICAÇÃO DE FIO-MÁQUINA*
}

\author{
Ana Carolina Ribeiro Duarte ${ }^{1}$ \\ Rodrigo Pinto de Siqueira ${ }^{2}$ \\ Fabiane Roberta Freitas da Silva ${ }^{3}$ \\ Manoela Fontana ${ }^{4}$ \\ Márcio Teodoro Fernandes 5 \\ Jefferson Fabrício Cardoso Lins $^{6}$
}

Resumo

Este trabalho teve por objetivo avaliar sistematicamente as etapas do processamento termomecânico de um aço SAE 1070 comercial. O aço foi trefilado a seco por 12 passes consecutivos com reduções médias entre $15 \%$ e $21 \%$. A deformação verdadeira acumulada ao final do $12^{\circ}$ passe foi de 2,52. Em seguida o material foi recozido a $1000^{\circ} \mathrm{C}$ por 10,20 , 30, 60 e 120 min. A caracterização microestrutural foi realizada com o auxílio da técnica de microscopia óptica, microscopia eletrônica de varredura e microscopia de força atômica. A rugosidade do material foi medida via microscopia confocal. O material teve ainda seu comportamento mecânico avaliado por meio de ensaio de dureza Vickers. Os fios de aço apresentaram a estrutura "curling" após o processo de trefilação. Essa estrutura foi substituída por uma estrutura perlítica refinada quando o material foi submetido ao recozimento. O ensaio de microdureza mostrou que, para restaurar as propriedades mecânicas do material, um recozimento entre 20 e 30 min seria suficiente. A análise da topografia revelou que o processo de trefilação altera consideravelmente a rugosidade do material.

Palavras-chave: Trefilação; Aço SAE 1070; Recozimento; Caracterização microestrutural.

\section{MICROSTRUCTURAL CHARACTERIZATION OF STEEL SAE 1070 OBTAINED BY THERMOMECHANICAL PROCESSING FOR MANUFACTURING OF WIRES}

\section{Abstract}

The aim of this work is microstructural characterization of SAE 1070 steel used in the manufacture of wire through thermomechanical processing. The steel was dry drawing for 12 consecutive pass with average reductions of $15 \%$ and $21 \%$. The true strain accumulated at the end of the $12^{\text {th }}$ pass was 2,52 . The material was subsequently annealed at $1000^{\circ} \mathrm{C}$ for $10,20,30$, 60 and $120 \mathrm{~min}$. The microstructural characterization was performed by the aid of the technique of optical microscopy, scanning by electron microscopy and atomic force microscopy. The roughness of material was measured with confocal microscopy. The material still had their mechanical properties evaluated by Vickers hardness test. The steel wires had curling structure after the drawing process. This structure was replaced by a fine pearlitic structure when the material was subjected to annealing. The microhardness test results showed that to an annealing between 20 and 30 minutes would be enough to restore the mechanical properties of the material. Analysis of topography showed that the drawing process greatly changes the surface roughness of the material.

Keywords: Wire drawing; Steel SAE 1070; Annealing; Microstructural characterization.

1 Eng. de Produção, Mestranda, Programa de Pós-graduação em Engenharia Metalúrgica, Universidade Federal Fluminense, Volta Redonda, RJ, Brasil.

2 Eng. de Materiais, Pós-doutorado, Programa de Pós-graduação em Engenharia Metalúrgica, Universidade Federal Fluminense, Volta Redonda, RJ, Brasil.

3 Eng. Metalúrgica, D.Sc, Pós-doutoranda, Programa de Pós-graduação em Engenharia Metalúrgica, Universidade Federal Fluminense, Volta Redonda, RJ, Brasil.

4 Eng. Metalúrgica, M.Sc., Doutoranda, Programa de Pós-graduação em Engenharia Metalúrgica, Universidade Federal Fluminense, Volta Redonda, RJ, Brasil.

5 Eng. Metalúrgica, Mestrando, Programa de Pós-graduação em Engenharia Metalúrgica, Universidade Federal Fluminense, Volta Redonda, RJ, Brasil.

6 Eng. Químico, D.Sc., Coordenador, Programa de Pós-graduação em Engenharia Metalúrgica, Universidade Federal Fluminense, Volta Redonda, RJ, Brasil.

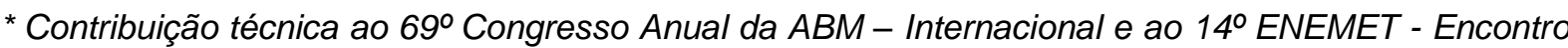
Nacional de Estudantes de Engenharia Metalúrgica, de Materiais e de Minas, 21 a 25 de julho de 2014, São Paulo, SP, Brasil.
} 


\section{INTRODUÇÃO}

Atualmente os fios metálicos de seção circular são largamente empregados pela indústria de transformação em diversos produtos, tais como cercas rurais, aplicações elétricas e cabos de todos os tipos. Além disso, os produtos trefilados são utilizados como matéria-prima para posterior processamento a frio, gerando uma enorme quantidade de produtos, entre eles eletrodo de solda, corda de piano, parafusos, arames, entre outros [1].

A maioria dos produtos trefilados tem aplicação para produtos de baixo valor de mercado como o caso de arames, parafusos e telas. Entretanto, existem aqueles que possuem maior valor agregado como é o caso do fio-máquina para aplicação em pneus. Este fato justifica o estudo dessa aplicação do processo de trefilação, devido ao seu elevado valor comercial, é necessário que o processo ocorra de forma a minimizar os defeitos de fabricação. O material utilizado na fabricação de fiomáquina, em grande parte dos casos, é um aço alto carbono com estrutura perlítica, pois apresenta elevada resistência ao desgaste e boa ductilidade, propriedades mecânicas que favorecem esse processo de conformação [2]. Essa característica pode ser atribuída à morfologia do constituinte lamelar ferrita-cementida, onde o constituinte com elevada dureza é incorporado no dúctil [3].

Recentemente, muito esforço tem sido feito para melhorar a resistência à tração de fios de aço alto carbono, com um valor experimental máximo de $5.7 \mathrm{GPa}$ [4]. Entretanto, muitos aspectos relacionados às propriedades dos fios de aço alto carbono ainda não estão claros, tais como, as alterações na microestrutura resultantes da trefilação, as propriedades de endurecimento características de aços perlíticos e o mecanismo de ocorrência de delaminação [5]. Neste trabalho, a evolução microestrutural deste aço durante um tratamento termomecânico foi o objeto de estudo principal, sendo assim avaliado em detalhe.

O aço SAE 1070 é um aço hipoeutetóide com estrutura perlítica com microestrutura escalonada constituída de colônias de lamelas em bloco [6]. Essa microestrutura consiste em uma fase extremamente resistente, a cementita, e a fase ferrita que apresenta boa ductilidade. Essas características microestruturais conferem aos aços perlíticos uma combinação de resistência e tenacidade que torna este material propício para aplicações estruturais, trilhos de estrada de ferro e fios de aço de alta resistência. As propriedades dos aços perlíticos são determinadas principalmente pelo espaçamento entre as lamelas de cementita e ferrita, o tamanho de grão austenítico prévio, o espaçamento interlamelar e o tamanho das colônias de perlita [3,7].

Uma das aplicações do aço SAE 1070 é na fabricação de fio-máquina através de um processamento termomecânico onde o material é trefilado e em seguida, é recozido para restauração das propriedades para novos passes de redução. Essas alterações nas propriedades mecânicas do aço são devido à deformação plástica sofrida durante a trefilação. Durante os passes de redução ocorre um desenvolvimento progressivo de deformação não uniforme e uma distribuição irregular das tensões residuais no aço. Há também um notável acréscimo no endurecimento plástico como consequência da perda da ductilidade relativa, que é aparente para os fios que apresentam os diâmetros menores [8,9].

O controle da evolução microestrutural durante o processamento termomecânico de um material é crítico para a determinação das propriedades mecânicas do produto final [10]. A literatura reporta que as propriedades mecânicas, tais como a dureza, a resistência e a tenacidade dos aços com teor de carbono de aproximadamente $0,7 \%$

\footnotetext{
* Contribuição técnica ao $69^{\circ}$ Congresso Anual da ABM - Internacional e ao 14ํㅡㄹ ENEMET - Encontro Nacional de Estudantes de Engenharia Metalúrgica, de Materiais e de Minas, 21 a 25 de julho de 2014, São Paulo, SP, Brasil.
} 


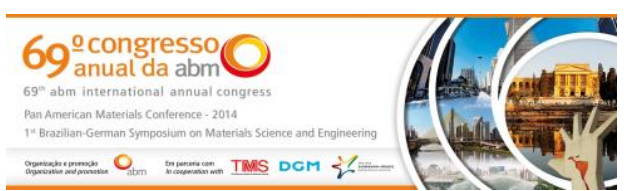

dependem fortemente do espaçamento interlamelar [11]. A ocorrência deste espaçamento está diretamente relacionada com a temperatura em que o material é recozido, onde é possível notar que o espaçamento interlamelar cresce à medida que a temperatura de recozimento aumenta. Logo, é possível relacionar a temperatura de recozimento deste aço com algumas propriedades mecânicas uma vez que, enquanto a dureza e a resistência crescem, a elongação e a tenacidade diminuem com o espaçamento interlamelar [12].

Este trabalho teve por objetivo avaliar sistematicamente as etapas do processamento termomecânico de um aço SAE 1070 comercial, analisando os efeitos da deformação plástica sofrida durante 0 processo de trefilação e acompanhando o processo de recristalização e recuperação ao longo do recozimento com o auxílio de técnicas de caracterização microestrutural. Outra finalidade deste estudo foi avaliar, do ponto de vista topográfico, a rugosidade do material bem como acompanhar o seu comportamento mecânico através de impressões de microdureza Vickers.

\section{MATERIAIS E MÉTODOS}

\subsection{O Material}

As amostras que foram utilizadas neste trabalho são provenientes de um material comercial fornecido por uma empresa. As amostras são do aço SAE 1070 sob a forma de fios de espessura que variam de 5,50 a 1,55 mm com tamanho aproximado de $25 \mathrm{~cm}$ de comprimento. As amostras foram divididas em 3 grupos: material de partida, material trefilado e material recozido. O material de partida são fios com 5,50 $\mathrm{mm}$ de diâmetro que foram produzidos por meio de laminação a quente com resfriamento contínuo não possuindo acabamento por usinagem ou deformação a frio. As amostras do material trefilado foram fornecidas segundo as características apresentadas no item 2.2.1. Finalmente, as amostras do material após o tratamento térmico, possuem espessura de $1,55 \mathrm{~mm}$ e foram recozidas a temperatura de $980^{\circ} \mathrm{C}$, com uma variação permitida entre $950^{\circ}$ e $1000^{\circ} \mathrm{C}$ com resfriamento contínuo no forno.

Tabela 1. Composição química do aço SAE 1070 (teores expressos em \% em peso)

\begin{tabular}{|ccccccccccc|}
\hline $\mathrm{S}$ & $\mathrm{C}$ & $\mathrm{Mn}$ & $\mathrm{P}$ & $\mathrm{Si}$ & $\mathrm{Al}$ & $\mathrm{Cr}$ & $\mathrm{Cu}$ & $\mathrm{Ni}$ & $\mathrm{Mo}$ & $\mathrm{N}$ \\
\hline 0,010 & 0,712 & 0,489 & 0,007 & 0,225 & 0,003 & 0,016 & 0,009 & 0,006 & 0,005 & 0,010 \\
\hline
\end{tabular}

\subsection{Métodos}

\subsubsection{Processamento termomecânico}

As amostras de fios do aço SAE 1070 de espessura de $5,50 \mathrm{~mm}$ tiveram a carepa removida de forma mecânica e, em seguida, foram trefiladas em 12 passes para atingir o diâmetro de 1,55 mm. As condições de trefilação encontram-se descritas na Tabela 2. No processo foram utilizadas fieiras de carboneto de tungstênio e a lubrificação foi realizada por meio do sabão a seco de estearato de sódio.

\footnotetext{
* Contribuição técnica ao $69^{\circ}$ Congresso Anual da ABM - Internacional e ao 14ํㅡㄹ ENEMET - Encontro Nacional de Estudantes de Engenharia Metalúrgica, de Materiais e de Minas, 21 a 25 de julho de 2014, São Paulo, SP, Brasil.
} 


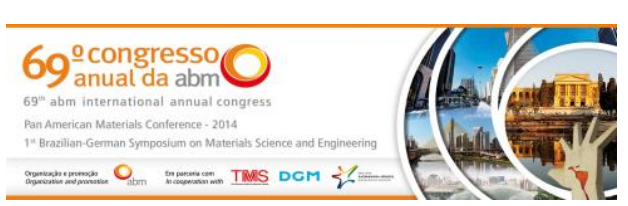

Tabela 2. Velocidade, Percentual de Redução e Deformação Verdadeira após cada passe de trefilação

\begin{tabular}{|ccccc|}
\hline $\begin{array}{c}\text { Passe de } \\
\text { Redução }\end{array}$ & $\begin{array}{c}\text { Velocidade } \\
(\mathrm{m} / \mathrm{mim})\end{array}$ & $\begin{array}{c}\text { Taxa de Redução Média } \\
\text { do Diâmetro do Fio (\%) }\end{array}$ & $\begin{array}{c}\text { Deformação } \\
\text { Verdadeira }\end{array}$ & $\begin{array}{c}\text { Deformação Verdadeira } \\
\text { Acumulada }\end{array}$ \\
\hline $1^{\circ}$ & 98 & 15,4 & 0,16 & 0,16 \\
\hline $2^{\circ}$ & 122 & 18,4 & 0,20 & 0,36 \\
\hline $3^{\circ}$ & 154 & 20,3 & 0,23 & 0,59 \\
\hline $4^{\circ}$ & 198 & 21,3 & 0,24 & 0,83 \\
\hline $5^{\circ}$ & 254 & 20,9 & 0,23 & 1,06 \\
\hline $6^{\circ}$ & 318 & 21,1 & 0,24 & 1,30 \\
\hline $7^{0}$ & 394 & 20,5 & 0,23 & 1,53 \\
\hline $8^{\circ}$ & 484 & 20,1 & 0,22 & 1,96 \\
\hline $9^{\circ}$ & 579 & 19,2 & 0,21 & 2,17 \\
\hline $10^{\circ}$ & 691 & 18,6 & 0,20 & 2,36 \\
\hline $11^{\circ}$ & 808 & 17,5 & 0,19 & 2,52 \\
\hline $12^{0}$ & 900 & 14,9 & 0,16 & \\
\hline
\end{tabular}

Após o processo de trefilação, as amostras do aço foram recozidas em um forno tubular a $1000^{\circ} \mathrm{C}$ durante os seguintes tempos: 10, 20, 30, 60 e 120 minutos. Estas condições foram escolhidas com o objetivo de se avaliar a estabilidade térmica, promover a eliminação das elevadas tensões introduzidas nos materiais, investigar a competição microestrutural e comparar os resultados as amostras fornecidas já recozidas em fluxo contínuo.

\subsubsection{Caracterização microestrutural}

As amostras foram cortadas em pedaços de aproximadamente $7 \mathrm{~mm}$ e embutidas em resina fenólica. Em seguida passaram pelas etapas de lixamento com as lixas de carbeto de silício de 320, 400, 600, 1000 e 1200. O polimento foi realizado com pasta de diamante com granulometria de 6, 3 e $1 \mu \mathrm{m}$ nos panos Top, Ram e Supra do fabricante Arotec respectivamente. Para o polimento final a solução de Sílica Coloidal diluída em água foi utilizada. A microestrutura foi revelada através do ataque químico feito com a solução de Nital 1\%. As amostram foram então, observadas no microscópio óptico modelo LEICA DM ILM, no microscópio eletrônico de varredura EVO MA10 da Zeiss e no microscópio de força atômica EasyCan 2 Flex AFM.

\subsubsection{Ensaios mecânicos}

Para avaliação do comportamento mecânico do material, foi realizado o ensaio de dureza Vickers em um microdurômetro da Shimadzu modelo HVM-2T com a carga de 300 gf durante 30 s.

\subsubsection{Análise de rugosidade}

A rugosidade do material foi analisada pelo Microscópio Confocal Axio CSM 700 da Zeiss. As amostras utilizadas possuíam comprimento aproximado de $10 \mathrm{~mm}$ e foram devidamente limpas para retirada da camada de oxidação.

\footnotetext{
* Contribuição técnica ao $69^{\circ}$ Congresso Anual da ABM - Internacional e ao 14ํㅡㄹ ENEMET - Encontro Nacional de Estudantes de Engenharia Metalúrgica, de Materiais e de Minas, 21 a 25 de julho de 2014, São Paulo, SP, Brasil.
} 


\section{RESULTADOS E DISCUSSÃO}

\subsection{Condição Inicial}

O material na condição inicial apresenta a microestrutura predominantemente perlítica com a presença de ferrita pró-eutetóide como pode ser observado na Figura 1. Essas características são compatíveis com o processo de laminação a quente ao qual o material foi submetido. A Figura $1 \mathrm{~b}$ é a ampliação da região sinalizada com um retângulo na Figura 1a, onde é possível observar com mais detalhe a ferrita pró-eutetóide. A Figura 2 permite observar de forma clara as lamelas de cementita e ferrita. As colônias que são compostas por lamelas alternadas apresentam diferentes orientações macroscópicas [13]. O material na condição inicial apresenta um valor de dureza igual a $319 \pm 12 \mathrm{HV}$.
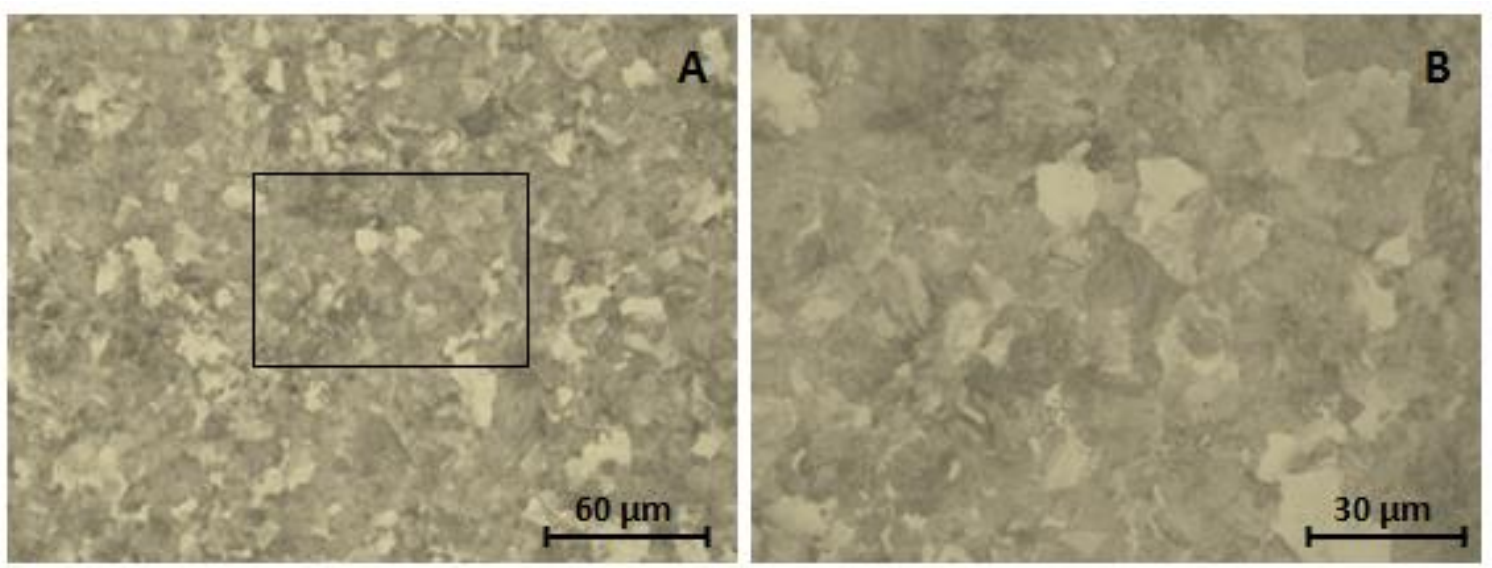

Figura 1. Imagens de MO do aço SAE 1070 na condição inicial. Seção transversal. (a) Ampliação de 200x. (b) Ampliação de 500x da região sinalizada em A.

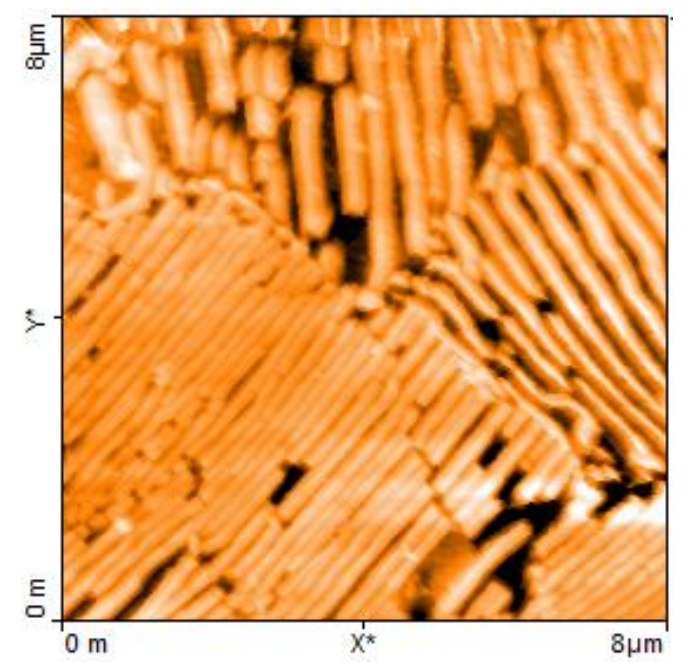

Figura 2. Imagem de MFA do aço SAE 1070 na condição inicial. Seção transversal.

\subsection{Deformação por Trefilação}

O material trefilado foi submetido a um elevado grau de deformação que implicou em alterações morfológicas em seus constituintes. A Figura 3 apresenta a microestrutura do fio de aço trefilado a uma deformação de 2,52. É possível observar, na seção transversal do fio, que há a formação de uma estrutura

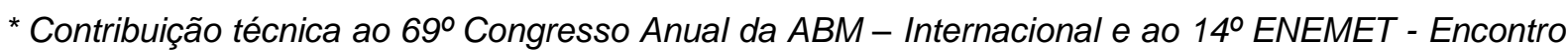
Nacional de Estudantes de Engenharia Metalúrgica, de Materiais e de Minas, 21 a 25 de julho de 2014, São Paulo, SP, Brasil. 


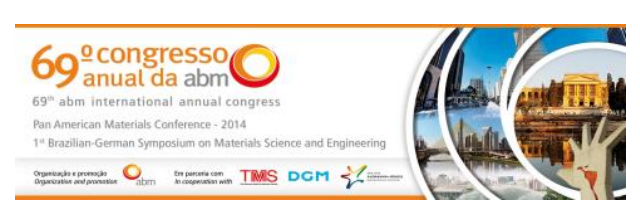

comumente denominada de "curling" devido à fratura das lamelas de cementita e a torção das lamelas de ferrita $[13,14]$. Essa estrutura é usualmente encontrada em fios de aço alto carbono submetidos ao processo de trefilação como mostra os trabalhos de Zhang [13] e Li [15]. Na estrutura "curling" as lamelas de cementita estão torcidas e fragmentadas em segmentos curtos e pequenas partículas dando a estrutura uma aparência relativamente homogênea em escala macroscópica [13,15].

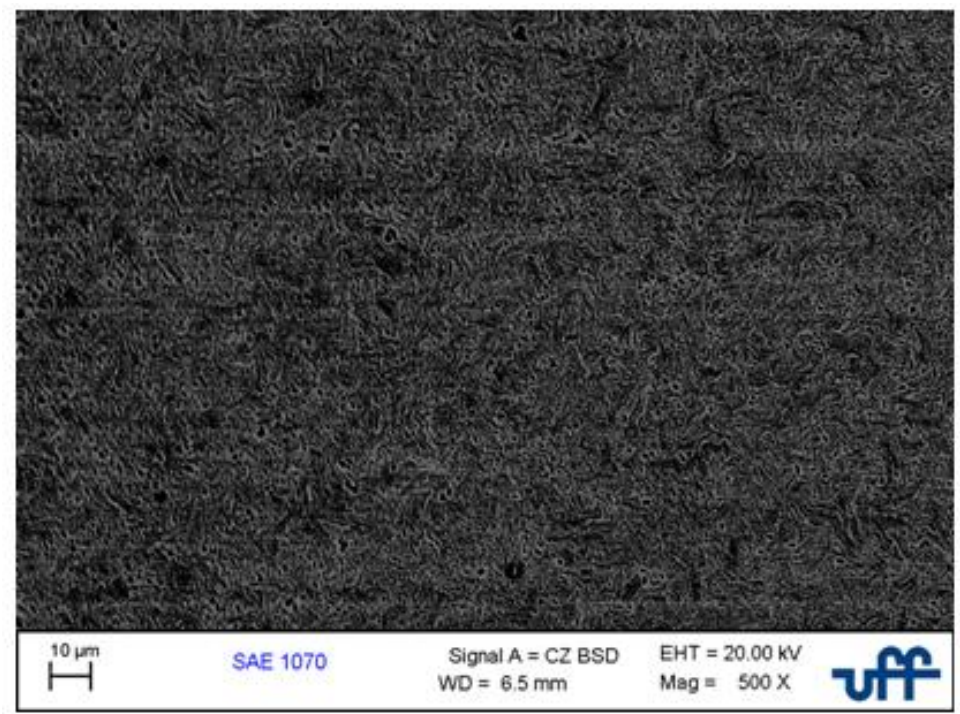

Figura 3. Imagem de MEV da estrutura "curling" do aço SAE 1070 deformado a frio com deformação de 2,52. Seção transversal.

A Figura 4 permite observar essa fragmentação e torção das lamelas, bem como verificar a redução considerável da espessura das lamelas, quando comparado com a Figura 2. Durante a trefilação, as lamelas que se encontravam paralelas a direção de trefilação alongaram-se, e as situadas em posições contrárias sofreram torção e dobramento [16]. Em consequência desse fenômeno a área superficial e a fração volumétrica das interfaces cementita/ferrita aumentam significativamente [17].

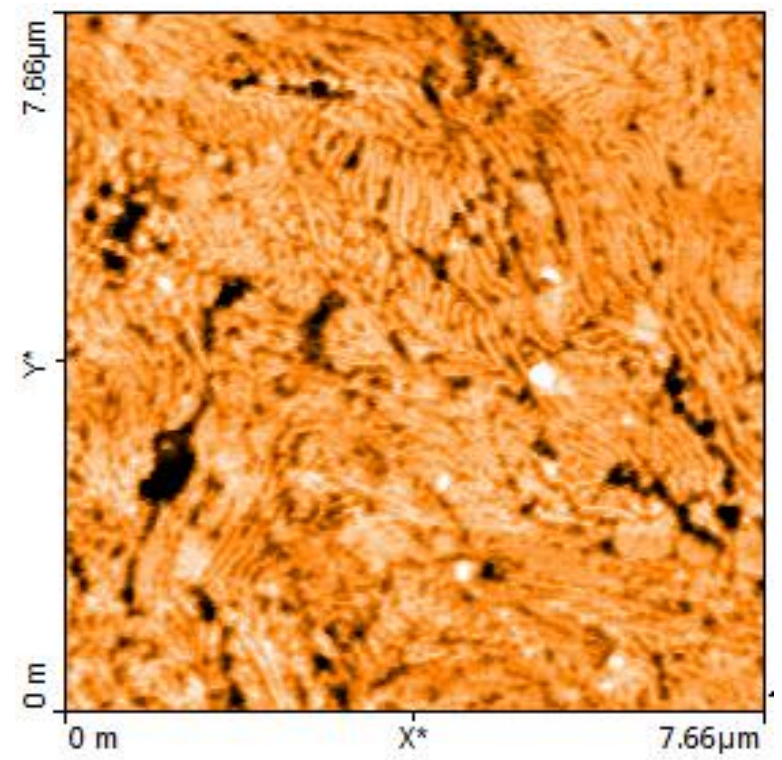

Figura 4. Imagem de MFA da micrografia do aço SAE 1070 deformado a frio com deformação de 2,52. Seção transversal.

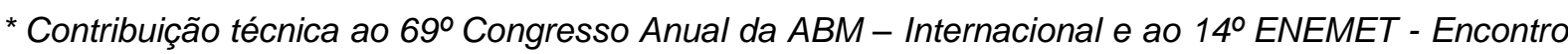
Nacional de Estudantes de Engenharia Metalúrgica, de Materiais e de Minas, 21 a 25 de julho de 2014, São Paulo, SP, Brasil.
} 


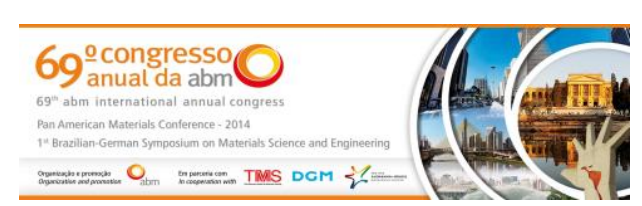

Mudanças na concentração e na distribuição dos elementos que constituem o material também ocorrem durante a deformação sofrida no processo de trefilação dos fios de aço. Li $[15,18]$, em seu estudo mostrou que durante a deformação do fio as lamelas de cementita se diluem e os átomos de carbono migram da fase cementita para a ferrita, alterando a concentração de equilíbrio dessas fases.

Outras alterações microestruturais também caracterizam um aço perlítico deformado. A redução do espaçamento interlamelar é um fator que se relaciona diretamente com a aplicação crescente de tensões no material, sendo descrito segundo a Relação de Hall-Petch [19]. Esse aumento contínuo de deformações ao longo do processo trefilação introduz discordâncias que se concentram nas interfaces entre as fases cementita e ferrita [20]. Além da concentração de discordância, outros mecanismos de endurecimento contribuem para o encruamento do material. $O$ aumento da fração volumétrica das interfaces cementita/ferrita e a elevada concentração de átomos de carbono na fase ferrita, conforme discutido anteriormente, agem como barreiras a movimentação das discordâncias. Essa interação é responsável pelo aumento considerável da resistência [14]. Esse fenômeno pode ser verificado através das alterações no comportamento mecânico do material, observado através do ensaio de dureza Vickers. O aço SAE 1070 na condição inicial apresentava um valor de microdureza igual a $319 \pm 12 \mathrm{HV}$ e após os 12 passes de trefilação, a microdureza do material aumentou para $538 \pm 28 \mathrm{HV}$.

\subsection{Tratamento Térmico de Recozimento}

Após a deformação plástica sofrida durante a trefilação, as propriedades mecânicas do material estão inadequadas para outros passes de redução. Por isso, para se obter um fio trefilado de dimensões ainda mais reduzidas é necessário um tratamento térmico intermediário afim de se reestabelecer as propriedades e características do material deformado. A Figura 5 mostra a microestrutura do material submetido a um recozimento a $1000^{\circ} \mathrm{C}$ durante $10 \mathrm{~min}$. É possível observar que a fragmentação e a torção das lamelas, característicos do material deformado, já não estão mais presentes. As lamelas apresentam uma redução significativa na sua espessura se comparado com o material na condição inicial. Ou seja, o recozimento em poucos minutos é capaz de substituir a estrutura de "curling" por uma estrutura lamelar refinada.

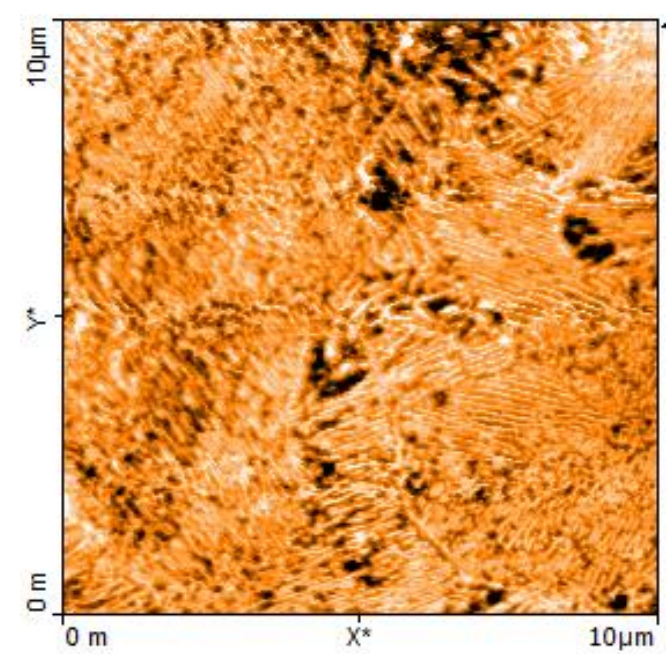

Figura 5. Imagem de MFA da micrografia do aço SAE 1070 recozido a $1000^{\circ} \mathrm{C}$ durante $10 \mathrm{mim}$. Seção transversal.

\footnotetext{
* Contribuição técnica ao $69^{\circ}$ Congresso Anual da ABM - Internacional e ao 14ํㅡㄹ ENEMET - Encontro Nacional de Estudantes de Engenharia Metalúrgica, de Materiais e de Minas, 21 a 25 de julho de 2014, São Paulo, SP, Brasil.
} 

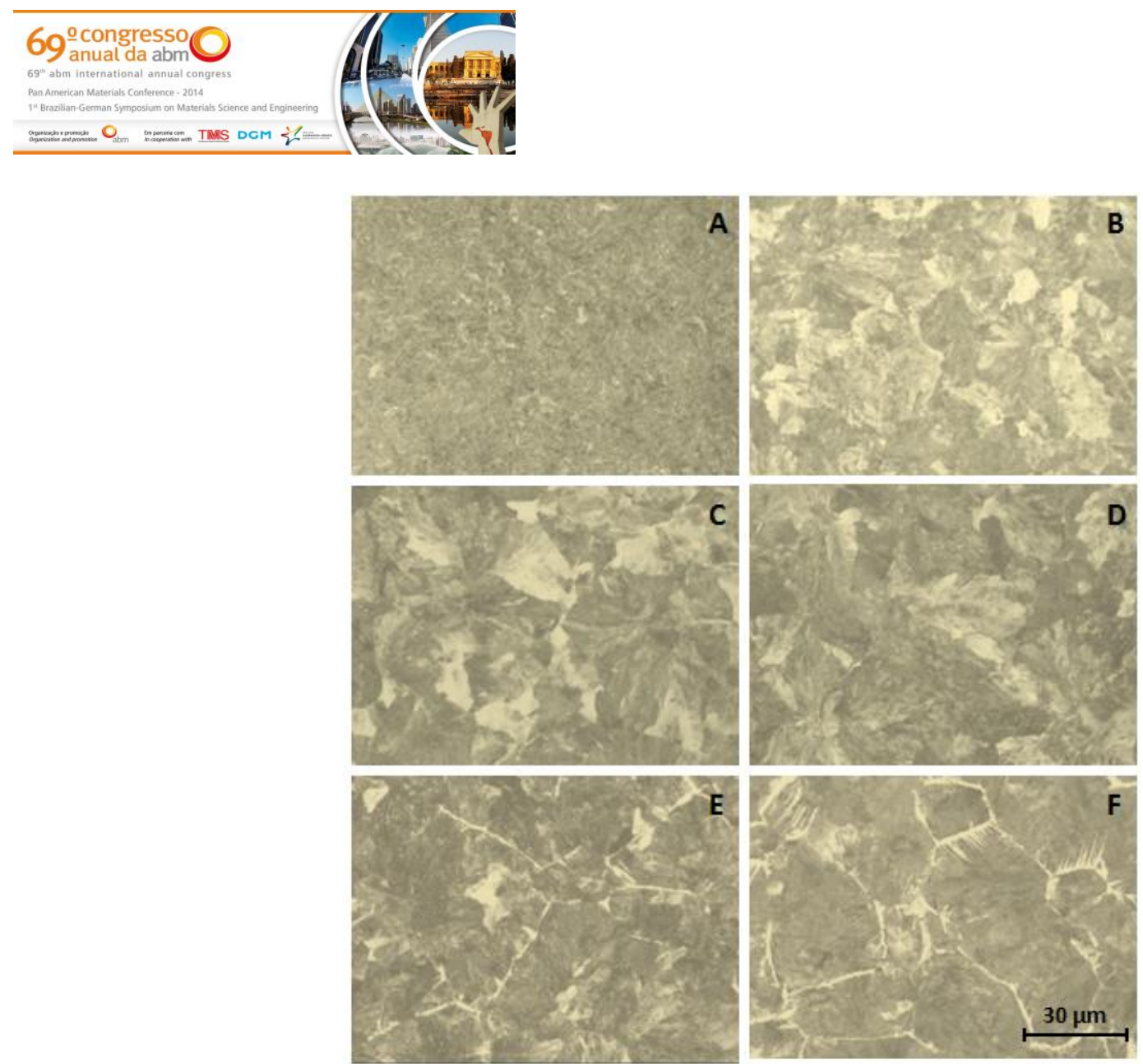

Figura 6. Imagens de $\mathrm{MO}$ da seção transversal. (A) Microestrutura do aço SAE 1070 deformado $\varepsilon=2,52$ e recozido a $1000^{\circ} \mathrm{C}$ durante (B) $10 \mathrm{~min},(C) 20 \mathrm{~min},(D) 30 \mathrm{~min},(E) 60 \mathrm{~min}$ e (F) $120 \mathrm{~min}$.

A Figura 6 apresenta a evolução microestrutural do aço SAE 1070 recozido durante diversos tempos. É possível obsevar que a estrutura de 'curling' apresentada na Figura 6⿳亠丷厂 logo no inicio do recozimento é substituída por uma estrutura recuperada onde há também a presença de grãos ferríticos recristalizados. Languillaume [21] mostrou que para um aço $0,7 \%$ p de carbono, o recozimento pós-deformação via trefilação resulta primeiramente na precipitação da fase cementita e, em seguida, na recuperação e na recristalização da microestrutura. A recuperação é responsável pela redução do nível de tensão interna nas lamelas de ferrita o que ativa termicamente a aniquilação e rearranjo das discordâncias. Simultaneamente, a recristalização dos domínios de ferrita também ocorre [21,22]. Com o prolongamento do tempo de recozimento, a recristalização da fase ferrita torna-se mais completa e a quantidade de discordâncias reduz intensamente de modo que os grãos de ferrita crescem continuamente de forma equiaxial e as partículas de cementita se distribuem nos contornos da fase ferrita [23]. Com o tempo de recozimento a partir de 60 min o processo de austenitização é mais efetivo e a nucleação dos grãos ferríticos ocorre na região dos contornos, sendo observado mais claramente na Figura 6e e $6 f$.

O gráfico da Figura 7 apresenta a dureza Vickers dos fios de aço recozido em função do tempo de recozimento. O tempo de recozimento igual a 0 min representa o material antes de passar pelo tratamento térmico, ou seja, o material deformado no processo de trefilação. Nota-se que houve um decréscimo da dureza, com o aumento do tempo de recozimento. Observa-se também que, o valor da dureza do material na condição inicial pode ser obtido com um tempo de recozimento entre 20 e $30 \mathrm{~min}$. Esse tempo de recozimento é suficiente para restaurar parcialmente as propriedades mecânicas do material.

* Contribuição técnica ao $69^{\circ}$ Congresso Anual da ABM - Internacional e ao 14ํㅡㄹ ENEMET - Encontro Nacional de Estudantes de Engenharia Metalúrgica, de Materiais e de Minas, 21 a 25 de julho de 2014, São Paulo, SP, Brasil. 

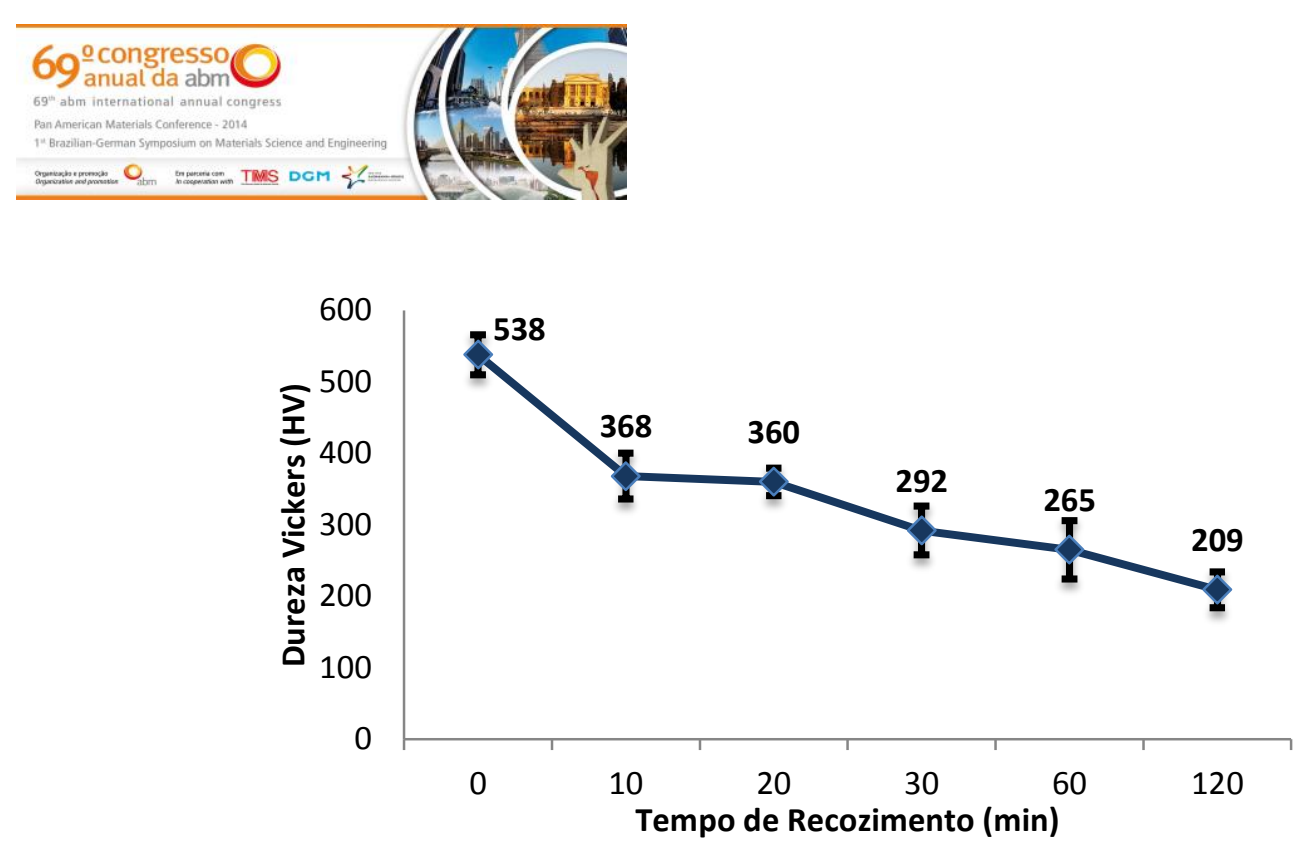

Figura 7. Gráfico da Dureza Vickers em função do tempo de recozimento.

\subsection{Análise de Rugosidade}

A rugosidade da superfície do material é responsável pela aderência do lubrificante na superfície de contato. Entretanto, outros parâmetros relevantes ao processo de trefilação como atrito e desgaste também se relacionam diretamente a rugosidade da superfície do material. A Tabela 3 apresenta alguns parâmetros de rugosidade do material de partida e após o processo de trefilação. As Figuras $8^{\mathrm{a}}$ e $8 \mathrm{~b}$ exibem 0 perfil topográfico do material de partida e do trefilado, respectivamente.

Tabela 3. Parâmetros de Rugosidade do Material de Partida e do Material Trefilado

\begin{tabular}{|ccc|}
\hline Parâmetro de Rugosidade & Material de Partida & Material Trefilado \\
\hline $\mathrm{Ra}$ & 1,899 & 3,985 \\
\hline $\mathrm{Rz}$ & 15,218 & 48,893 \\
\hline $\mathrm{Rt}$ & 18,233 & 101,890 \\
\hline $\mathrm{Rsk}$ & $-0,081$ & 0,166 \\
\hline
\end{tabular}
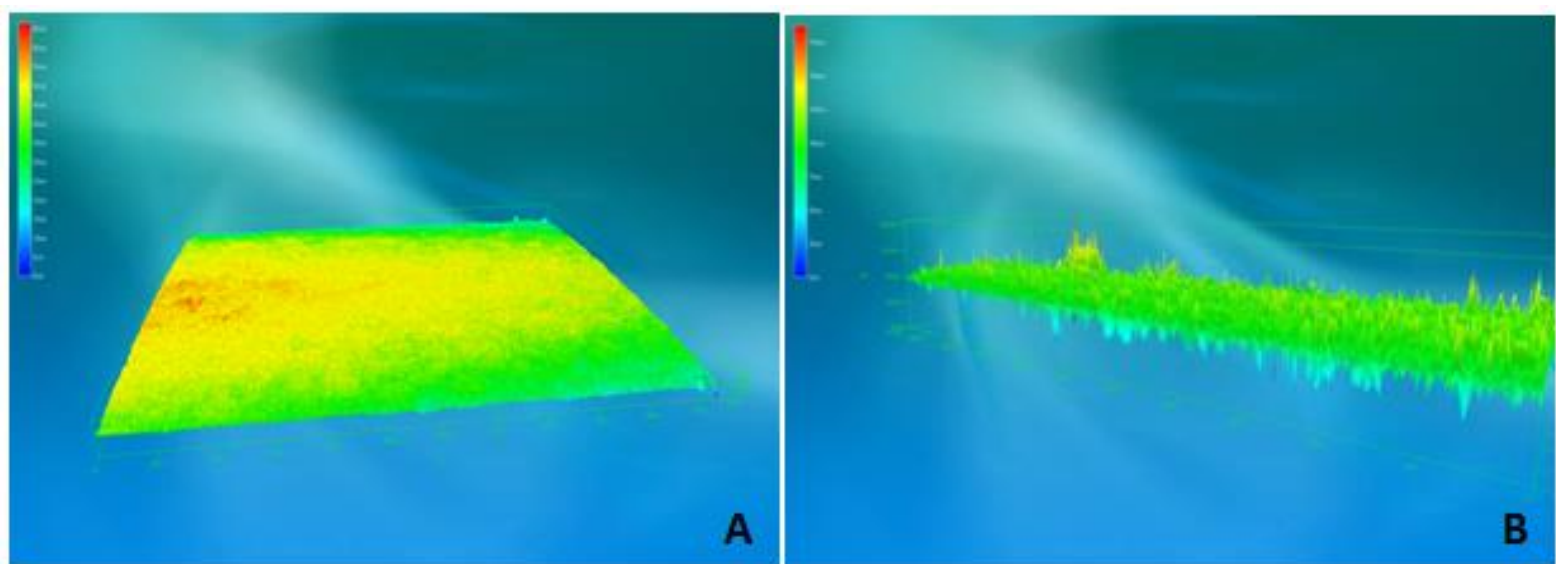

Figura 8. Microscópio Confocal.Topografia do fio de aço SAE 1070. (a) Condição Inicial. Área analisada $793553 \mu \mathrm{m}^{2}$. (b) Após o Processo de Trefilação. Área analisada $289772 \mu \mathrm{m}^{2}$.

Comparando os dados fornecidos na Tabela 3 é possível observar que, apesar da Rugosidade Média $(\mathrm{Ra})$ entre os dois materiais serem próximas, o perfil topográfico entre eles é bem distinto como mostra as Figuras $8^{\underline{a}}$ e $8 b$. Esse fato pode ser confirmado com os outros parâmetros de rugosidade. A Rugosidade Total (Rz) que representa a distância entre o pico mais alto e o vale mais profundo é bem distinta

\footnotetext{
* Contribuição técnica ao 69ำ Congresso Anual da ABM - Internacional e ao 14ํㅡㄹ ENEMET - Encontro Nacional de Estudantes de Engenharia Metalúrgica, de Materiais e de Minas, 21 a 25 de julho de 2014, São Paulo, SP, Brasil.
} 


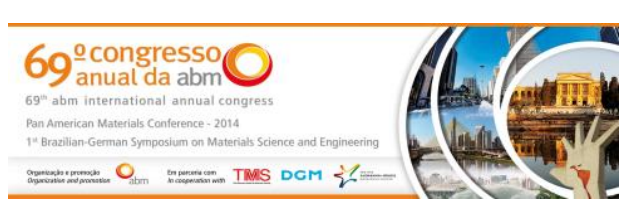

entre os dois materiais, assim como a Rugosidade Máxima (Rt). Fica evidente desta forma, que o material que passou pelo processo de trefilação apresenta picos e vales com amplitudes consideravelmente maiores que o material na condição inicial. O Fator de Assimetria (Rsk) também comprova essa diferença de topografia, pois o material de partida possui valor negativo indicando que o perfil de rugosidade possui menos picos. A elevada diferença entre os parâmetros Ra e Rt apresentada pelo material trefilado pode implicar em consequências negativas para o sistema de lubrificação. Segundo Wong [24], este fator pode levar a formação de uma região de desgaste devido à redução do filme lubrificante provocada durante o processo de trefilação.

\section{CONCLUSÃO}

A estrutura "curling" apresentada pelo aço SAE 1070 quando submetido ao processo de trefilação, é substituída por uma estrutura predominantemente recuperada logo nos primeiros minutos do recozimento. Há uma redução significativa na espessura das lamelas alternadas de ferrita e cementita, formando uma estrutura lamelar refinada. O ensaio de dureza mostrou que para restaurar as propriedades mecânicas do material, um recozimento entre 20 e 30 min seria suficiente. A análise da topografia revelou que o processo de trefilação altera consideravelmente a rugosidade do material e há a formação de picos que podem comprometer a lubrificação gerando zonas de atrito.

\section{Agradecimentos}

À Capes e ao CNPQ pelo auxílio financeiro concedido.

\section{REFERÊNCIAS}

1 Magalhães $F$, Pertence $A$, Campos $H$, Aguilar $M$, Cetlin $P$. Evolução de defeitos superficiais em barras de cobre submetidas ao processo de trefilação. In: 60 Congresso Brasileiro de Engenharia de Fabricação; 2011; Caxias do Sul, Brasil. COBEF; 2011. p.745-753.

2 Dougherty JD, Srivatsan T, Padovan J. Fatigue crack propagation and closure behavior of modified 1070 steel: experimental results. Engineering Fracture Mechanics. 1997:56:167-187.

3 Lampman S. Materials selection and design. ASM International, 1997; 20.

4 Ochiai, M, Nishida S, Ohba H. Application of hypereutectoid steel for development of high strength steel wire. Tetsu-to-Hagane. 1993;2:79-110.

5 Tarui T, Takahashi J, Tashiro H, Maruyama M, Nishida S. Microstructure control and strengthening of high-carbon steel wires. Nippon Steel Tech Rep. 2005:1:56-61.

6 Morooka S, Tomota Y, Kamiyama T. Heterogeneous deformation behavior studied by in situ neutron diffraction during tensile deformation for ferrite, martensite and pearlite steels. ISIJ International. 2008;48:525-530.

7 Taleff E, Lewandowski J, Pourladian,B. Microstructure - property relationships in pearlitic eutectoid and hypereutectoid carbon steels. JOM. 2002;54:25-30.

8 Camp JM, Francis CB. The Making, Shaping, and Treating of Steel. Pittsburgh: United States Steel Company; 1957.

9 Celentando J, Palacios A. Simulation and experimental validation of multiple-step wire drawing processes. Finite Elements in Analysis and Design. 2009;45:163-180.

10 Yassar R. Microstructure History Effect during Sequential Thermomechanical Processing. Materials Science and Engineering A. 2008;494:52-60.

\footnotetext{
* Contribuição técnica ao $69^{\circ}$ Congresso Anual da ABM - Internacional e ao 14ํㅡㄹ ENEMET - Encontro Nacional de Estudantes de Engenharia Metalúrgica, de Materiais e de Minas, 21 a 25 de julho de 2014, São Paulo, SP, Brasil.
} 


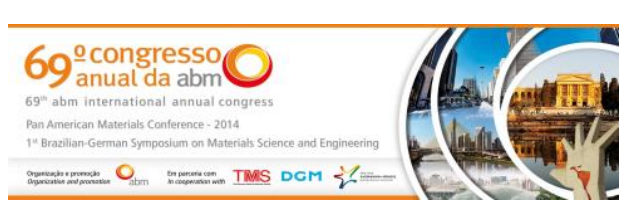

11 Ay K, Mondal D. The effect of interlamellar spacing on strength of pearlite in annealed eutectoid and hypoeutectoid plain carbon steels. Acta metallurgica et materialia. $1991 ; 39(10): 2201-08$.

12 Modi P, Mondal DP, Prasad BK. Abrasive wear behavior of a high carbon steel: effects of microstructure and experimental parameters and correlation with mechanical properties. Materials Science and Engineering A. 2003;43:235-242.

13 Zhang X, Godfrey A, Hansen N, Huang X. Hierarchical structures in cold-drawn pearlitic steel wire. Acta Materialia. 2013;61:4898-4909

14 Zhang X, Godfrey A, Hansen N, Huang X, Liu Q. Microstructure and strengthening mechanisms in cold-drawn pearlite steel wire. Acta Materialia. 2011;59:3422-30.

15 Li Y, Choi P, Goto S, Borchers C, Raabe D, Kirchheim R. Evolution of strength and microstructure during annealing of heavily cold-drawn 6.3 Gpa hypereutectoid pearlitic steel wire. Acta Materialia. 2012;60:4005-16.

16 Kumar P, Gurao N, Haldar A, Suwas S. Progressive Changes in the Microstructure and Texture in Pearlitic Steel during Wire Drawing. ISIJ International. 2011;51:679-684.

17 Nishida S, Yoshie A, Imagumbai M. Work Hardening of Hypereutectoid and Eutectoid Steels during Drawing. ISIJ International. 1998;38:177-186.

$18 \mathrm{Li} \mathrm{Y,} \mathrm{Choi} \mathrm{P,} \mathrm{Goto} \mathrm{S,} \mathrm{Borchers} \mathrm{C,} \mathrm{Raabe} \mathrm{D,} \mathrm{Kirchheim} \mathrm{R,} \mathrm{Westerkamp} \mathrm{S.} \mathrm{Atomic} \mathrm{scale}$ investigation of redistribution of alloying elements in pearlitic steel wires upon colddrawing and annealing. Ultramicroscopy. 2013;132:233-238.

19 Zelin M. Microstructure evolution in pearlitic steels during wire drawing. Acta Materialia. 2002;50:4431-47.

20 Choo WY, Bae CM. Drawing Behavior of Pearlitic Steel Wire Rods Controlled by Boron Addition in Medium Carbon Steel. ISIJ International. 2002;42:47-51.

21 Languillaume J, Kapelski G, Baudelet B. Evolution of the tensile strength in heavily cold drawn and annealed pearlitic steel wires. Materials Letters. 1997;33:241-245.

22 Languillaume J, Kapelski G, Baudelet B. Cementite dissolution in heavily cold drawn pearlitic steel wires. Acta Materialia. 1997;45:1201-12.

23 Lv Z, Sun S, Wang M, Jiang P, Fu W. Effect of alloying elements addition on coarsening behavior of pearlitic cementite particles after severe cold rolling and annealing. Materials Science and Engineering: A. 2008;489:107-112.

24 Wong W, Ying J, Zhou M. Effect of surface roughness parameters on mixed lubrication characteristics. Tribology International. 2006;39:522-527.

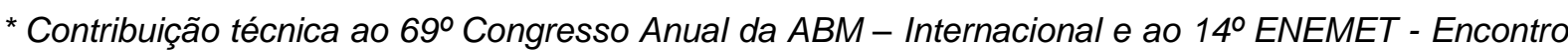
Nacional de Estudantes de Engenharia Metalúrgica, de Materiais e de Minas, 21 a 25 de julho de 2014, São Paulo, SP, Brasil.
} 